\title{
Da 'bancada da segurança' à 'bancada da bala': Deputados-policiais no legislativo paulista e discursos sobre segurança pública
}

Roberta Heleno Novello ${ }^{1}$

${ }^{1}$ Universidade de São Paulo, São Paulo, SP, Brasil

Marcos César Alvarez ${ }^{2}$

${ }^{2}$ Universidade de São Paulo, São Paulo, SP, Brasil

Policiais e militares têm migrado para a política partidária desde a democratização no Brasil. Este artigo investiga esse fenômeno no legislativo paulista em dois contextos distintos. Por meio de pesquisa documental, são comparadas a chamada "bancada da bala" da 18a legislatura (20152019) e a "bancada da segurança", eleita pela primeira vez na 11a legislatura (1987-1991). Apesar de os dois grupos apresentarem continuidades em relação à segurança pública, há novas negociações e disputas pela política de direitos humanos. Discutese também como a "bancada da bala" reorganiza conservadorismos no campo político ao abrir espaços de conexão com grupos diversos.

Palavras-chave: policiais na política, conservadorismo, discurso, direitos humanos, legislativo
Police and military officers have been migrating to institutional party politics since the democratization period in Brazil. From the 'Security Caucus' to the 'Bullet Caucus': Police Officers as Congressmen in the São Paulo Legislative Assembly and Discourses on Public Safety analyzes former officer's discourses at São Paulo's state parliament in different contexts. Drawing from document analysis, the so-called "bullet caucus" of the 18th legislature (2015-2019) was compared to the "security caucus" elected for the first time in the 11th legislature (1987-1991). Although these groups have shown similarities concerning public security, new negotiation strategies, and a dispute over human rights policy have been observed. The paper argues that the "bullet caucus" reorganizes conservatism in the political field by opening spaces of connection with diverse groups.

Keywords: police officers in politics, conservatism, discourse, human rights, parliament

\section{Introdução'}

A expressão "bancada da bala" é uma construção social e midiática que descreve bancadas suprapartidárias compostas, majoritariamente, por egressos das forças de segurança cujas plataformas políticas e discursivas se organizam em torno de temas relacionados à segurança pública. É uma categoria qualificadora de políticos que costumam ser caracterizados pela visão autoritária de controle social, por uma tensão constante com a política de direitos humanos e por representarem as corporações policiais e os interesses da indústria armamentista.

Esses grupos têm sido objeto de amplo debate devido ao fortalecimento da influência das bancadas suprapartidárias nos processos decisórios e na definição de agendas do Legislativo. "Bancada da bala" também remete à questão da inserção de policiais na política institucional democrática, o que não é um fenômeno novo, dado que são atores regulares no Legislativo da Nova República. No entanto, é patente o aumento da expressão política das forças de segurança no cenário 
brasileiro: em 2018 um militar da reserva, Jair Bolsonaro, foi eleito para a Presidência da República, e com ele foram eleitos 73 policiais e militares para cargos do Legislativo, frequentemente como campeões de voto ${ }^{2}$ e em uma quantia quatro vezes maior que as eleições de 2014.

Essa projeção de policiais e militares no cenário político tem levantado algumas hipóteses. Autores relacionam essas bancadas a um conservadorismo laico à brasileira inscrito em um fenômeno de superação de uma direita envergonhada (QUADROS, 2015) e a um conservadorismo de ideologia securitário-autoritária (FAGANELLO, 2017), considerando-as um dos vetores de uma onda conservadora que atua em uma linha de força repressiva e punitiva $\left(\right.$ ALMEIDA, 2017) ${ }^{3}$. Com frequência, esses grupos também são compreendidos como indicadores de processos bastante contemporâneos, como o chamado "giro punitivo" (GARLAND, 2008; SOZZO, 2012) e a formação de um "Estado penal" (WACQUANT, 2009, 2010, 2011), ou como expressões de um legado autoritário brasileiro (CHAUÍ, 2013; CALDEIRA, 2000; ADORNO e IZUMINO, 1999; ZALUAR, 1999; PINHEIRO, 1991, 1997; O'DONNELL, 1986).

O presente artigo busca contribuir para esse debate analisando como se estruturam as práticas e os discursos desses grupos em nível local e suas transformações ao longo do tempo. Busca-se, sobretudo, qualificar o que tem sido nomeado como "conservadorismo" entre eles e como isso se organiza em um universo empírico específico. Foram analisados comparativamente as continuidades e os desdobramentos nos discursos (FOUCAULT, 2008, 2014) de dois grupos de "deputados-policiais" que se organizaram em momentos distintos na Assembleia Legislativa de São Paulo (Alesp) $)^{4}$ a chamada "bancada da bala", eleita na 18 legislatura (2015-2019), e a "bancada da segurança", eleita pela primeira vez em 1986. As práticas dos deputados da $18^{\mathrm{a}}$ legislatura foram analisadas por meio das suas proposições legislativas, atas das sessões e frentes parlamentares, atas das Comissões de Segurança Pública e de direitos humanos, relatórios das Comissões Parlamentares de Inquérito (CPIs), além das plataformas de mídia e das produções dos deputados em jornais e revistas. Esses discursos foram cotejados com a bibliografia da chamada "bancada da segurança", com base nos trabalhos de Caldeira (2000) e Cymrot (2015), e no mapeamento da produção legislativa dos deputados.

A "bancada da segurança" foi eleita durante a transição democrática, período em que os estados adquiriram grande relevância política ${ }^{5}$. Em 1982, pela primeira vez em quase duas décadas, a oposição venceu nos principais estados e passou a controlar 3/4 do Produto Interno Bruto (PIB). Os governadores dos estados mais desenvolvidos adquiriram, portanto, centralidade e poder político, o que possibilitou que liderassem o movimento de redemocratização do país (ABRUCIO, 1994, pp. 166-170). 
Além de comandarem verdadeiras máquinas de fazer política que são os governos estaduais, contrapunham a legitimidade por eles conquistada nas urnas à origem arbitrária do poder dos militares. Portanto, no contexto de transição, os grandes condutores do processo político são os governadores de estado. Foram atores decisivos no Diretas-Já e posteriormente, na disputa presidencial indireta, tanto que um deles, Tancredo Neves, tornou-se presidente (Ibid., p. 170).

Foi justamente nesse contexto que se elegeu o primeiro grupo de deputados egressos das forças policiais e militares no legislativo paulista. Esse grupo, identificado por Caldeira (2000), organizou-se em oposição ao governo de Franco Montoro (1983-1987), primeiro governador eleito em São Paulo por voto direto. Sua política e a de seu secretário de Justiça, José Carlos Dias, foram caracterizadas por tentativas de controle da violência policial e pela ampliação da política de direitos humanos, principalmente em relação à rede prisional, o que ficou conhecido como “políticas de humanização" (HIGA, ALVAREZ e SALLA, 2017, p. 117).

A oposição ao governo de Montoro e às políticas de direitos humanos foi promovida por diversos setores - incluindo a Associação dos Delegados de Polícia do Estado de São Paulo (Adpesp) e o programa de rádio de Afanásio Jazadji - que, em parte, formaram o grupo de deputados estaduais autodenominado "bancada da segurança". Segundo Caldeira (2000), pertenciam a essa bancada: coronel Antônio Erasmo Dias (PDS e PPR), comandante da chamada “invasão da PUC”6 em 1977 e do combate à guerrilha no Vale do Ribeira e deputado estadual na Alesp entre 1987 e 1999; Conte Lopes (PDS e PTB), que ingressou nas Rondas Ostensivas Tobias de Aguiar (Rota) em 1974, no auge da ditadura militar, foi afastado do policiamento de rua durante o governo de Montoro e foi deputado estadual entre 1987 e 2010; Afanásio Jazadji (PFL, PDS, PST), radialista, deputado estadual entre 1987 e 2007; Ubiratan Guimarães (PDS e PTB), que combateu a guerrilha no Vale do Ribeira e comandou a invasão policial na Casa de Detenção em 1992, tendo sido deputado entre 1994 e 2006; Hilkias de Oliveira (PDT), delegado, deputado estadual entre 1987 e 1995; e o coronel Edson Ferrarini (PFL, PL, PTB), deputado estadual entre 1987 e 2014.

Geralmente esses grupos são identificados nos meios de comunicação como representantes dos interesses da corporação policial e defensores de pautas punitivistas. Mas cabe ressaltar que a defesa dessas pautas não lhes é exclusiva, sendo compartilhada por diversos deputados de partidos distintos. É possível afirmar, também, que todos os deputados exercem práticas que podem ser qualificadas como "clientelistas" e "corporativas", conforme sua área de atuação, base eleitoral, trajetória e cultura profissional anterior. Os deputados egressos das forças de segurança apresentam maneiras específicas de se referir a determinados objetos, empregar conceitos e organizá-los em estratégias que indicam a regularidade de uma prática. No caso, são práticas relacionadas tanto às suas trajetórias profissionais em uma instituição histórica e regulamentada - dotada de saberes, valores e competências específicas -, quanto à sua posição ocupada no Legislativo, em que se 
traduzem e se enunciam questões da instituição policial. Vê-se, assim, afinidade com o argumento de que o plenário "seria lócus privilegiado para deputados-policiais expressarem, sob a legitimidade de um pronunciamento parlamentar, elementos da subcultura policial" (CYMROT, 2015, p. 311).

Todavia, defende-se aqui que o oposto do argumento de Cymrot também é verdadeiro: é sob a legitimidade da cultura policial que se expressam pronunciamentos parlamentares endereçados a diferentes audiências. Este artigo evidencia como determinados discursos são estruturantes e possibilitam a comunicação entre elementos da formação institucional e da cultura policial de rua (MUNIZ, 1999) e outras formas de profunda moralização e ordenação simbólica da vida social, como descrito por Caldeira (2000) sobre a "fala do crime":

narrativas que promovem uma reordenação simbólica do mundo a partir de experiências de medo e violência. Produtos do pensamento classificatório que elabora preconceitos, naturalizam desigualdades e produzem figuras destinadas a simbolizar o mal e explicar o crime. A fala do crime produz uma visão do mundo social que contempla e organiza outras experiências e dimensões da vida (Ibid., p. 36).

Como exemplo, há o desejo expresso de restauração de um passado mítico, marcado pela conformidade moral e pela homogeneização de comportamentos, em que não haveria conflitos e crimes (MUNIZ, 1999, p. 19). A disputa de interesses, os dissensos e conflitos não são compreendidos como elementos legítimos e constitutivos da vida social e devem, portanto, ser suprimidos. A partir dessas concepções são estruturadas categorias binárias de pertencimento de "bem/nós" versus “mal/eles” em que deveriam ser distribuídos direitos aos primeiros e formas autoritárias de controle aos segundos.

Argumenta-se aqui que as articulações entre punição e moralidade constituem o potencial de difusão desses discursos e o meio pelo qual são abertos espaços de conexão com outras audiências, não apenas com as forças de segurança. A cultura e formação institucional desses deputados, ou seja, o saber-fazer advindo da experiência, confere legitimidade a esses discursos e conservadorismos sociais que privilegiam determinadas formas de conhecer e pensar concretamente (MANNHEIM, 1986).

A primeira seção deste artigo apresenta uma série de continuidades, permeadas por tensões, nos discursos e práticas do que se entende como "bancadas da bala" ao longo do tempo. Entre elas, destaca-se como a matriz da guerra - entendida como grade de inteligibilidade da vida social - continua estruturante no modo de se pensar o processamento do conflito. Busca-se mostrar como o discurso do enfrentamento têm fortes efeitos em termos de audiência, reprodução e constituição política desses grupos, além de seus efeitos institucionais.

Na segunda seção, discute-se as transformações em torno dos direitos humanos como objeto de disputa desses grupos. Primeiramente, os discursos se orientavam no sentido de negar essa 
política; por volta dos anos 2000, contudo, é possível notar matizes de negociação e disputa por sua interpretação e efetivação. Ressalta-se que não se trata da substituição do discurso anterior: no levantamento realizado, é possível encontrar, no mesmo período, discursos convergentes e divergentes entre si. A disputa pela interpretação dos direitos humanos se torna especialmente forte no grupo da $18^{\mathrm{a}}$ legislatura, nas atuações em comissões permanentes e frentes parlamentares sobre o tema, além da produção legislativa.

$\mathrm{Na}$ terceira e última seção, discute-se como esses grupos de deputados egressos das forças repressivas mobilizam discursos para diferentes grupos políticos e audiências, não apenas para a corporação policial e militar. Explicita-se também a formação de conexões entre as "bancadas da bala" e as chamadas "bancadas evangélicas", com base nos discursos que articulam temas sobre punição e moralidade.

\section{Discurso da guerra: matriz de inteligibilidade social}

Dado o conjunto de interpretações sobre as "bancadas da bala" em termos de conservadorismo, giro punitivo contemporâneo e/ou permanência autoritária, analisou-se como esses elementos e tendências se organizam nos grupos da Alesp. Evidenciou-se quais as permanências, regularidades e atualizações nas práticas da "bancada da segurança", eleita pela primeira vez na $11^{\text {a }}$ legislatura, e a "bancada da bala", eleita na $18^{\mathrm{a}}$ legislatura.

Entre as continuidades identificadas, o que mais se destaca é como o discurso da guerra (BENETTI, 2017; GARLAND, 1999; MUNIZ, 1999; PINHEIRO, 1982) tem uma expressiva trajetória de continuidade entre a "bancada da bala" e a "bancada da segurança". Nessas narrativas, as forças de segurança são compreendidas como dotadas de uma missão superior: defender a sociedade contra o mal. Isso pode ser observado no discurso de assunção de comando da Rota proferido pelo futuro deputado, Cel. Paulo Telhada, e lido por Cel. Edson Ferrarini no pequeno expediente:

\footnotetext{
Como soldados cristãos que somos, sempre seguindo os passos da lei e da justiça, fui buscar orientação no Livro Sagrado (...) que estas palavras sirvam de orientação, ensinamento e ânimo a todos aqui presentes (...) pois estamos do lado da justiça, do bem, somos instrumentos de Deus para manter a ordem, a paz e a tranquilidade da população paulista. Enfrentamos diuturnamente o mal, a criminalidade que teima em agir contra os cidadãos de bem (Cel. Ferrarini, 74a sessão ordinária, 01/06/2009).
}

Nesse excerto, fica evidente a combinação entre uma linguagem bélica e religiosa para se tratar da atividade policial; isso foi recorrentemente observado em toda a pesquisa. 
A matriz da guerra implica o desenvolvimento de uma disposição pragmática, urgente e hierarquizante. Na política do "matar ou morrer", é produzida uma perspectiva da vida social hierarquizada em dois grandes grupos opostos: de um lado, as forças de segurança e os cidadãos de bem; do outro, o resto dos indivíduos, caracterizados por um conjunto de comportamentos e discursos que simbolizam o universo do mal. Apesar de essas demarcações apresentarem regularidade ao longo do tempo, suas transformações ficam ao sabor das fronteiras morais e políticas. No jogo das classificações binárias, situa-se a concepção de direitos fundamentais como algo de natureza meritocrática, facultativa e destinada aos que pertencem às categorias "cidadãos de bem", "pai de família trabalhador" e "cumpridor da lei". Os demais estão às margens da comunidade política e humana e devem ser combatidos.

Essa trajetória de continuidade entre deputados oriundos das polícias é perceptível na comparação de discursos quase miméticos entre deputados cujas trajetórias na Polícia Militar do Estado de São Paulo (PMESP) se deram em momentos bastante distintos: Conte Lopes, que ingressou em 1967 e foi afastado em 1985, e Paulo Telhada, que ingressou em 1983 e se aposentou em 2009:

\footnotetext{
O que vem a matéria? Simplesmente analisando a morte de "pessoas". Volto a repetir: não são pessoas. São criminosos, são bandidos que se não estivessem na rua cometendo crime, se não enfrentassem a polícia, evidentemente não morreriam (Lopes, 70a sessão ordinária, 27/05/2008).
}

Se tiver que ficar viúva, que fique a mulher do bandido (Lopes, 88a sessão ordinária, 03/08/2010).

Quero parabenizar o tenente, primeiro, por trabalhar dando sustento para a família; segundo, por estar vivo; e terceiro, por graças a Deus ter mandado três vagabundos para o colo do capeta. (...) quem não gosta de polícia que mata bandido, quem é? É o próprio bandido ou quem defende bandido (Cel. Telhada, 163a sessão ordinária, 09/11/2016).

A população está refém do crime, estamos à beira do caos. O ECA [Estatuto da Criança e do Adolescente] criou um monstro, criou inimigos, assassinos terríveis. Hoje o menor de idade mata, estupra e barbariza sabendo que é protegido pela lei (Cel. Telhada, programa de TV Ponto de Equilíbrio, 29/03/2015).

Remete-se aqui à histórica concepção militarista na produção da ordem pública no Brasil, bem como às heranças da Doutrina de Segurança Nacional, quando as polícias foram direcionadas para atividades de segurança interna para combater "inimigos do regime" (MUNIZ, 1999). Permanecem alegorias associadas à simbologia da guerra presente nas práticas policiais, no imaginário público e na mídia por meio de registros como "combate", "confronto", "inimigos” o que "[repõe] paralelismos entre as atividades policiais e as forças de defesa nacional" (Ibid., p.113). Exemplar nesse sentido é o discurso de Cel. Ferrarini, que demonstra o vínculo entre o sagrado e a atividade policial, bem como a produção de inimigos como signos que ameaçam uma ordem, um modo de vida e uma missão superior: 
Podemos não ser compreendidos, ser injustiçados pela imprensa. As nossas melhores atuações não são cobertas pela imprensa. Não faz mal, mas também tenho informações, deputado Conte Lopes, [de] que o mais populoso inferno é aquele habitado por todos os inimigos da Polícia Militar. O inferno está lotado deles. Estão queimando porque um dia não compreenderam a Polícia Militar. Quem sabe lá, no fogo do inferno, eles vão nos entender (Cel. Ferrarini, 67a sessão solene, 09/12/2005).

Como pode ser visto no discurso acima, policiais se veem como uma minoria atacada por diversas instâncias e "reagem publicamente indignados aos controles democráticos, não tanto porque temem que exponham seus desvios, mas porque sua existência atesta que o próprio servidor da lei poder ser suspeito" (CYMROT, 2015, p. 156). Nesse sentido, a pesquisa identificou um conjunto de narrativas sobre uma "cultura de impunidade e inversão de valores" que expressa o sentimento compartilhado desses grupos sobre uma profunda crise de autoridade e ruptura moral dos tempos atuais. São discursos que narram as dificuldades de adaptação da instituição policial aos controles externos, à exigência de resultados em relação ao crime por meio do uso moderado da força e da garantia de direitos fundamentais.

Nessa chave, diversas figuras inimigas são produzidas, principalmente as que exercem algum controle externo às atividades policiais e defendem políticas de direitos humanos. Associa-se, assim, direta ou indiretamente, a política e agentes defensores dos direitos humanos ao universo simbólico do crime.

\section{Direitos humanos em disputa}

As campanhas eleitorais de 2018 se distinguem pela forte presença de discursos violentos e abertamente contrários aos direitos humanos, demarcando também a entrada da extrema direita ${ }^{7}$ na esfera pública. Entre inúmeros exemplos, destaca-se como Bolsonaro defendeu o fuzilamento de concorrentes políticos, homenageou torturadores, discriminou populações indígenas, quilombolas e LGBT. A cabo Katia Sastre transmitiu em seu horário eleitoral um vídeo em que atirava duas vezes no peito de um homem armado que assaltava uma escola ${ }^{8}$. João Dória (PSDB), por sua vez, eleito em 2018 governador de São Paulo, afirmou que em seu governo a polícia iria "atirar para matar". Observa-se, assim, a intensa circulação e popularidade eleitoral de discursos que mobilizam sentimentos de insegurança e indignação da população em relação ao crime e à violência, em sentidos que advogam formas autoritárias de controle social, exaltam a violência estatal e formas de “justiça privada" e fomentam hostilidades sociais contra determinados grupos.

No entanto, a popularidade de discursos anti-direitos humanos e a articulação de grupos políticos em torno deles não constituem um fenômeno necessariamente novo no Brasil. Caldeira (2000) evidencia como, durante a redemocratização, esses discursos articularam a experiência da violência nas cidades e as inseguranças de uma sociedade recém-egressa de um regime autoritário. 
A partir dos anos 1980, lutas políticas e discursivas vão constituindo uma espécie de campo em que os direitos humanos passam a ser objeto de disputa. Geralmente, essa narrativa é contada em termos de polarização: de um lado, a agenda de direitos humanos se transformou em linguagem fundamental para os principais grupos e atores políticos que conduziram a redemocratização; de outro, grupos e atores favoráveis e ou ligados ao regime militar encontraram nos discursos que opõem direitos humanos à segurança pública um meio estratégico de resistência e de novas estratégias de atuação em relação aos processos em curso. Esses discursos se tornaram bastante populares, sendo cristalizados em máximas como "direitos humanos, privilégio de bandidos" e "bandido bom é bandido morto". Atores que os mobilizaram receberam apoio popular, frequentemente convertido em sucesso eleitoral ${ }^{9}$.

Esses discursos circularam por diferentes setores e nunca foram monopolizados por agentes ou partidos específicos na política institucional. Contudo, atores socializados nas instituições de controle social, em especial policiais e militares, são uma das categorias profissionais que mais os convertem em capital político, uma vez que sua experiência profissional se torna um recurso facilmente instrumentalizável e produtivo para a agenda eleitoral (BERLATTO, CODATO e BOLOGNESI, 2016).

Conforme já mencionado, a eleição dos integrantes da "bancada da segurança" na $11^{\text {a }}$ legislatura (1987-1991) se deu com base na campanha de desqualificação das políticas de direitos humanos do governo Montoro (1983-1987). Preconceitos e estereótipos compartilhados por grandes parcelas da população foram habilmente articulados nos meios de comunicação (CALDEIRA, 2000, p. 346), resultando em uma campanha bem-sucedida em que o respeito aos direitos humanos foi associado ao "privilégio de bandidos". A partir dela, diversas entidades e indivíduos defensores dos direitos humanos foram desqualificados. Em um trecho do manifesto da Adpesp, publicado em 4 de outubro de 1985, lê-se:

\footnotetext{
Os tempos atuais são de intranquilidade para você e de total garantia para os que matam, roubam e estupram. A sua família é destroçada e o seu patrimônio, conseguido à custa de muito sacrifício, é tranquilamente subtraído. E por que isto acontece? A resposta você sabe. Acreditando em promessas, escolhemos o governador errado, o partido errado, o PMDB [Partido do Movimento Democrático Brasileiro] (...) Eles, os bandidos, são protegidos pelos tais "direitos humanos", coisa que o governo acha que você, cidadão honesto e trabalhador, não merece (Ibid., p. 347).
}

Nesse mesmo sentido, a Folha de S. Paulo havia publicado um artigo do Cel. Erasmo Dias em 1983:

A insatisfação da população quanto à polícia, exigindo inclusive uma atuação mais dura, no que pode ser considerado responsabilidade do governo Montoro, decorre da filosofia alardeada dos "direitos humanos" aplicada de modo unilateral mais em proveito de bandidos e marginais. Filosofia que privilegia o marginal, dando-Ihe o "direito" de andar armado, assaltando, matando e estuprando (ERASMO DIAS, 11/09/1983 in CALDEIRA, 2000, p. 347). 
Percebe-se como o discurso contrário às políticas de direitos humanos é construído em oposição a interlocutores não abstratos. Elas não são apresentadas como derivação de direitos inerentes, universais e como princípio do Estado brasileiro vis-à-vis suas relações internacionais, mas como políticas instrumentalizadas por grupos e entidades específicos. Contudo, constatamos um deslocamento fundamental nos discursos dessas bancadas em relação aos direitos humanos. Nas primeiras legislaturas, a "bancada da segurança" apresentava discursos de negação dessas políticas em registros como "direitos humanos é privilégio de bandidos", "bandido bom é bandido morto" e correlatas (CALDEIRA, 2000). Já por volta dos anos 2000 é possível notar o surgimento de discursos apresentando matizes de negociação e disputa pela efetivação dessas políticas:

\footnotetext{
Falar mal da Polícia Militar é fácil, mas tenho informações precisas de que no bairro mais populoso do inferno estão todos aqueles que não gostam da Polícia Militar. Estão todos lá exatamente por essa incompreensão. Algumas pessoas distorcem a filosofia dos direitos humanos, e as incompreensões da imprensa que apenas destaca o lado negativo (Ferrarini, 61 a sessão solene, 13/12/2004).
}

Entrou Montoro com direitos humanos. Os direitos humanos são para todo o mundo, até para o policial. Quem não quer ter direitos humanos? Eu acho que todos têm que ter. Agora, como podemos viver em uma terra onde não temos certeza se, daqui a dez minutos, estamos vivos? Nós temos que mudar alguma coisa. (...) aproveito para dizer que também sou favorável aos direitos humanos de todo mundo, inclusive do policial (Lopes, 13a sessão extraordinária, 27/04/2001).

Esse deslocamento é muito mais acentuado entre os deputados da "bancada da bala". A gramática democrático-humanista passa a ser amplamente adotada em seus discursos no plenário, nas justificativas de projetos de lei, na formação de frentes parlamentares, nos requerimentos por CPIs etc. São práticas que mobilizam como fundamento exatamente a defesa dos direitos humanos e do Estado democrático de direito.

Nessa legislatura, não se observou nos discursos a negação da política de direitos humanos, e sim a disputa por seus sentidos e pela imposição de uma agenda ${ }^{10}$.

Partidinhos de esquerda, pessoas que gostam de tumultuar, estão preocupados com a minha designação [para a Comissão de Direitos Humanos da Alesp]. Os que gritam aí sobre direitos humanos estão preocupados em ganhar dinheiro com suas ONG's, com as suas investidas, a preocupação do pessoal é financeira. (...) A nossa preocupação aqui não [é financeira], é trabalhar pela população, é lutar pelo cidadão. Na nossa Comissão de Direitos Humanos, nós vamos falar sim das vítimas da violência, das forças de defesa. (...) aqui nessa comissão, nós vamos nos preocupar com os humanos e principalmente com os humanos direitos (Cel. Telhada, 35a sessão ordinária, 08/05/2015).

Sr. Ariel de Castro, o senhor, como outras pessoas que usam o manto dos direitos humanos para defender infrator da lei, isso sim gera violência, essa forma errada de serviço à sociedade, de defender infrator à lei (Cel. Camilo, 137a sessão ordinária, 20/09/2016). 
Como se pode ver nos discursos dos coronéis Telhada e Camilo, o objetivo é resgatar a política de direitos humanos das mãos de "setores que distorcem os direitos humanos, ao conferir demasiada importância aos infratores da lei e ignorar as vítimas do crime". Segundo os deputados, esses setores se "escudam sob o manto dos direitos humanos" para proteger infratores da lei, difamar as forças de segurança e enriquecer. Seus discursos também indicam como o fomento de hostilidades, nesse caso contra defensores de direitos humanos, produz solidariedade entre audiência, além de operar como prática de resistência institucional aos controles externos e às disputas de narrativas.

Hostilidades são mobilizadas principalmente ao Judiciário, às figuras e entidades relacionadas aos direitos humanos, à imprensa e à população prisional. Isso fica claro na comparação de Telhada entre o tratamento jurídico dispensado a policiais e a criminosos:

Nem assaltante de banco, nem matador de polícia e criança passam por essa situação, mas o policial militar passa. Basta alguém acusá-lo para que ele seja recolhido preso. (...) esse é o país que põe polícia na cadeia e ladrão na rua (Cel. Telhada, 109a sessão ordinária, 25/09/2015).

A contraposição de direitos e condições de vida de "cidadãos de bem" versus criminosos é estratégia recorrente. Fomenta-se um imaginário da prisão como um lugar de regalias - a que os "cidadãos de bem" não teriam acesso - concedidas a uma população composta exclusivamente pelos perpetradores dos crimes mais perversos. Conte Lopes ilustra bem essa tendência ao opor a dieta dos trabalhadores da lavoura à dos presidiários:

\footnotetext{
São presos que comem uma "quentinha" de manhã, à tarde e à noite. Uma alimentação bonita, que os trabalhadores comuns não recebem. Eles comem carne todos os dias. Aquele que trabalha na lavoura, que planta arroz e feijão para nós, não pode comer e o bandido come todos os dias. Inclusive tem uma nutricionista para ver se a comida está quente, se está tudo certo para o vagabundo que atacou a sociedade, que roubou, estuprou, matou e vive uma inversão de valores (Conte Lopes, 115 a sessão ordinária, 21/08/2000).
}

Discursos e outras práticas semelhantes são mobilizados contra figuras e instituições que procuram exercer controle externo às atividades da polícia. Esse controle é compreendido como objetivando ameaçar a legitimidade das polícias, coagi-las e atrapalhá-las.

E nós esperamos que na modificação que o governador venha a fazer que se siga pelo menos a mesma forma de trabalho, que é de policiais nas ruas, no combate ao crime, e não o medo de direitos humanos (Conte Lopes, 193a sessão ordinária, 15/12/2004).

Os bons policiais estão todos encostados e o que não está fica na corda bamba. Qualquer telefonema para a ouvidoria, esse policial bom é afastado. Então o policial não pode trabalhar (Conte Lopes, 101 a sessão ordinária, $11 / 07 / 2002)$ 
Como aponta o discurso de Conte Lopes, a Ouvidoria de Polícia do Estado de São Paulo enfrenta desde sua criação ${ }^{11}$ oposição de deputados oriundos das forças de segurança. Em novembro de 1995, a Folha de S. Paulo fez uma entrevista com Benedito Domingos Mariano, ouvidor de polícia no período. A reportagem pontuava como "setores ligados às polícias, representados pelos deputados Erasmo Dias e Conte Lopes, criticavam Mariano por ser ligado às entidades de direitos humanos" (FOLHA DE S.PAULO, 1995).

Em 1998 houve uma profusão de projetos na Alesp em torno da Ouvidoria. A deputada Rosmary Corrêa (PMDB), delegada de polícia, propôs o projeto de lei complementar $\mathrm{n}^{\mathrm{o}}$ 0020/1998, que proibia a instituição de considerar as denúncias anônimas nas estatísticas divulgadas pelo órgão. O deputado Ubiratan Guimarães apresentou três projetos: 1) noo 007/1998, que proibia o ouvidor de ser filiado a partidos políticos quando estivesse no cargo e por igual

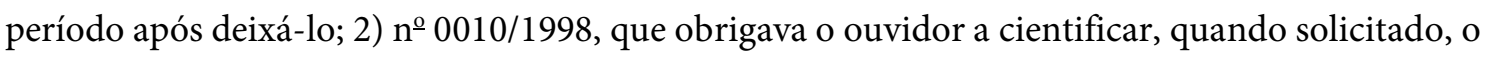
secretário de Segurança, o delegado-geral da Polícia Civil, o comandante-geral da Polícia Militar e os membros do conselho executivo sobre as denúncias, reclamações e representações recebidas; e 3) no 0012/1998, que eliminava todas as gratificações do cargo.

Tal modo de operação continua sendo mobilizado. Os deputados da "bancada da bala" da 18 a legislatura afirmavam que Júlio Neves, então ouvidor da polícia, tinha por objetivo "destruir a imagem da corporação", e o qualificavam como "palpiteiro" e "falador". O ápice dessa oposição culminou com o pedido de Cel. Camilo ao governador pela imediata exoneração de Neves, movimento aliado à elaboração de um projeto de lei para modificar a escolha do ouvidor por meio da inclusão de um dispositivo para exonerá-lo durante o mandato. Além disso, o coronel convocou o ouvidor a prestar esclarecimentos para a Comissão de Segurança Pública e Assuntos Penitenciários sobre declarações feitas à imprensa.

A resistência aos controles externos também se manifesta na maneira como esses deputados defendem o monopólio e a legitimidade de seu saber. Seus discursos frequentemente reivindicam a experiência prática dos policiais, em sua relação direta com o crime e a violência:

\footnotetext{
Vejo muitas pessoas falarem sobre segurança. Às vezes penso: qualquer dia, irei perguntar quando ele prendeu um bandido. Eles são todos especialistas. Vejo até coronéis que, na época em que eu era policial, viraram especialistas em segurança e em criticarem a polícia, mas eles nunca pegaram um bandido (Lopes, 12a sessão solene, 19/04/2004).

O sr. [Coronel José Vicente] é especialista em nada. O sr. nunca defrontou com ninguém, nunca tirou vítima de cativeiro, nunca trocou tiro. Você não sabe de nada (Olim, 125a sessão ordinária, 05/09/2017).
}

Como pode ser visto nesses discursos, é a partir da experiência que esses atores reivindicam a autoridade de seu saber, exatamente pela qualidade de ser prático, concreto, direto e, portanto, 
verdadeiro. Tal postura se contrapõe àquela do "especialista", cujo conhecimento é considerado abstrato, idealista, político e mediado. Essas práticas agenciam o saber adquirido pela experiência da "cultura policial das ruas" (MUNIZ, 1999) como forma de interdição e legitimação dos discursos intra e extracorporação.

O tema com maior repercussão e sobreposição de vozes de diferentes campos é o uso da força letal. É exatamente por conta dessa polifonia que os deputados despendem boa parte do tempo e espaço institucional para defender atuações policiais e deslegitimar as fontes de questionamento. $\mathrm{O}$ discurso do delegado Olim, por exemplo, impõe diversas interdições à pergunta de uma jornalista sobre uma ação policial que culminou na morte de dez assaltantes que, em conjunto, levaram 139 tiros.

\footnotetext{
Primeiro, quero explicar para essa Vera Magalhães que ela não entende nada de polícia. Segundo, nós não podemos contar tudo para ela, como funciona a investigação (...) quem não conhece, quem não sabe como que é, não fala. Vai investigar primeiro para ver como funciona. (...) quem não está na cena do crime não pode falar (Delegado Olim, 125a sessão ordinária, 05/09/2017).
}

Como se pode observar, esses discursos concebem o uso da força letal e seus protocolos como algo de natureza extremamente técnica, cujo aprendizado só é possível com a experiência. Portanto, esse debate é compreendido como monopólio da polícia, e assim, pareceres e questionamentos externos são ilegítimos.

A partir do saber-fazer policial como linha divisória de legitimidade de discursos e o tema dos direitos humanos tratado em termos não universais, é possível notar a especificidade das relações tecidas entre o abstrato e o concreto nesses discursos. Segundo Mannheim (1986), o conservadorismo como estilo de pensamento implica uma forma de conhecer e pensar concretamente, preocupa-se com a ação imediata, com os detalhes concretos em mudança, restringindo seu alcance às redondezas imediatas de onde se está localizado. Implica também uma forma distinta de experienciar o tempo: os acontecimentos são experienciados em termos ancorados no passado; a história é pensada em termos mais espaciais e de coexistência do que temporais e de sucessão. Essa questão remete à forma de pensar a sociedade como elo entre gerações passadas, presentes e futuras, além da interrelação entre as instituições sociais e a primazia da sociedade sobre os indivíduos. Nesse quadro, instituições como a igreja, costumes e tradições têm papel destacado.

Tendo isso em vista, voltemos à maneira como são estruturadas as categorias bem e mal nos discursos dessas bancadas, a saber, como conjuntos de atividades, moralidades e escolhas em relação às instituições tradicionais. A família, a religião, a disciplina, o respeito à autoridade e o civismo são compreendidos como elementos garantidores de boa ordem e de combate à degeneração moral. O mal, por sua vez, é simbolizado por indivíduos que escolheram rejeitar e investir contra essas instituições e moralidades, conforme a seguinte fala de Telhada: 
Dos meus amigos, metade virou polícia, metade virou bandido. É tudo opção, porque eles abandonaram a escola, a igreja, não respeitam o pai e a mãe, não têm profissão, não ouviram o pastor, o ancião (Cel. Telhada, programa de TV Ponto de Equilíbrio, 29/03/2015).

A partir das tendências discutidas - recorrer à matriz da guerra como grade de inteligibilidade da vida social, conferir centralidade às instituições tradicionais, adotar uma visão extremamente moralista da vida social, preponderância do pensamento concreto -, argumentase aqui que as maneiras com que essas práticas discursivas coproduzem sentidos de ordem, moralidade e civilidade, bem como suas respectivas oposições, indicam um repertório compartilhado que repõe e atualiza valores conservadores nos campos político e de controle do crime. Além disso, ao analisar a $18^{\text {a }}$ legislatura, observou-se um processo de vinculação de atores sociais em torno de consensos, experiências e elementos morais e normativos que orientam sua interação em um sentido comum. Em específico, há um lastro comum de formas variadas de conservadorismos e desejo de retorno a um passado mítico que articula conexões parciais entre grupos do Legislativo e audiências pretendidas, como se discutirá a seguir.

\section{Discursos conservadores e espaços de conexão}

Durante a pesquisa, observou-se articulações entre diferentes atores da $18^{\text {a }}$ legislatura em uma atuação cujo sentido configura o que é entendido atualmente por muitos autores como "onda conservadora". No entanto, como afirma Almeida (2017), trata-se de uma onda que quebra em várias direções, composta por grupos com posicionamentos distintos, mas que se articulam em conexões parciais conformando um sentido comum.

Os deputados da "bancada da bala" agenciam uma renovada construção simbólica do medo e da insegurança, circunscrevendo atividades e condutas como problemas de crise moral que necessitam de intervenção. Além disso, disputam o sentido e o escopo da função preventiva da polícia como agente regulador de comportamentos e difusor de valores, por meio da qual se fomentam iniciativas como o Programa Educacional de Resistência às Drogas (Proerd), os colégios das polícias militares e o retorno da educação moral e cívica nas escolas. Tal agenda de ampliação da função preventiva das polícias demonstra o movimento dos deputados oriundos das forças de segurança para agir sobre o que identificam como causas não apenas do crime, mas de uma série de problemas sociais.

Aqui na Assembleia Legislativa trabalhamos com duas frentes. Uma é a Frente da Segurança. Temos uma Frente Parlamentar com esse nome, e que eu coordeno. Ela trabalha na consequência: nós trabalhamos no final da ponta. Quando alguma coisa não funciona - a Segurança, a Polícia -, nós vamos agir. E falar de outro lado que 
trabalhamos aqui porque julgamos extremamente importante. Aliás, mais importante até do que trabalhar na consequência, é trabalhar na causa, nos jovens, na criança; trabalhar na internalização de valores para que as crianças tenham nas escolas valores morais, éticos e de cidadania para saber exercer a sua cidadania (Camilo, 112a sessão ordinária, 23/08/2016).

Encontra-se aqui toda uma sociologia espontânea na qual a corrupção, a violência, a impunidade e os comportamentos antissociais figuram como os principais problemas contemporâneos, cujas causas estão na "desestruturação da instituição familiar e religiosa" produtora de indivíduos destituídos de valores necessários para a condução de uma vida correta e civilizada. Nesses discursos, que conjugam a autoridade estatal e as autoridades tradicionais, formam-se espaços de conexão com deputados que representam interesses das comunidades evangélicas ${ }^{12}$.

Nota-se um envolvimento significativo de deputados evangélicos nas áreas de segurança pública e nas práticas mais "policialescas" da atividade legislativa. Por exemplo, dos 11 deputados efetivos da Comissão de Segurança Pública e Assuntos Penitenciários, cinco pertencem à Frente Parlamentar Evangélica; e 40\% dos deputados que compõem a Frente de Segurança Pública, criada por Camilo, são evangélicos. A Frente Parlamentar pela Defesa da Vida e da Família, concentrada em pautas de restrição de direitos (LGBT, aborto) e historicamente associada a movimentos religiosos, é composta por mais de $81 \%$ de deputados que pertencem à Frente de Segurança Pública. Essa tendência também é observada nas composições das CPIs e na formulação de projetos de lei que visam a formas de penalização ${ }^{13}$.

Sugere-se aqui, a partir do caso da $18^{\mathrm{a}}$ legislatura, que há um movimento duplo de securitização da agenda de deputados da área de representatividade evangélica e de evangelização da agenda de deputados da área de segurança pública. O lançamento da Frente Parlamentar da Família, Cultura e Cidadania, em 14 de agosto de 2015, ilustra o espaço de conexão entre esses grupos: ela defende diferentes estratégias de controle do crime, desde a intervenção tradicional bélica até a função preventiva da polícia como uma força moralizadora a atuar no controle de condutas e na formação de crianças e adolescentes. Essa frente tem como objetivo:

\footnotetext{
Evidenciar a importância da família como célula base da sociedade; entender a família como a primeira escola onde se forjam o caráter e a dignidade da pessoa humana; promover ações para estimular a convivência harmônica e responsável entre as pessoas; promover, principalmente entre as crianças e adolescentes, os valores éticos, morais e espirituais que regem a vida em sociedade; alavancar políticas públicas, voltadas para o fortalecimento dos princípios familiares, cívicos e culturais. ${ }^{14}$
}

As conexões entre esses grupos são marcadas por um desejo comum de restauração de um "estado mítico de sociedade, de conformidade moral no qual não ocorriam conflitos, crimes e litígios" (MUNIZ, 1999, p. 19). São discursos marcados pela linguagem da retomada de algo perdido: "retomar a certeza de punição, retomar os valores da família". Observa-se, sobretudo, 
como as articulações entre punição e moralidade são pontos de conexão entre os grupos. Por exemplo, a ideia do "empreendimento de si", marca do discurso neopentecostal (ALMEIDA, 2017), é relacionada com a concepção de crime. Nos discursos dos "deputados-policiais", as fronteiras entre "cidadão de bem" e universo do crime são demarcadas pela ideia de empreendimento moral; o crime é compreendido como uma escolha racional e moral feita pelo indivíduo que se distanciou das instituições, condutas e valores que constituem a categoria do "bem". Nesse sentido, as "bancadas da bala" e "bancadas evangélicas" multiplicam instâncias legislativas cujas temáticas inscrevem diversos problemas sociais e objetos de disputa no campo da punição e moralidade. Esses espaços tornam-se lugares privilegiados de circulação discursiva que tem como efeitos certa alocação de recursos e tempo institucional, o fortalecimento de alianças, a visibilidade e a exposição de determinados atores e organizações.

Em suma, esses grupos articulam e promovem concepções profundamente moralizadoras da vida pública, segundo as quais conflitos e heterogeneidades são extremamente disruptivos para a ordem social e devem ser suprimidos por meio da punição. Trata-se de uma leitura que, no limite, nega a política, lugar por excelência da negociação, do debate e da institucionalização do conflito.

\section{Conclusões}

Os discursos e as demais práticas da "bancada da bala" e da "bancada da segurança" no Poder Legislativo paulista apresentaram poucos deslocamentos, mesmo estado as bancadas situadas em diferentes períodos. Observou-se, na pesquisa, como essas tramas discursivas repõem e atualizam práticas e concepções autoritárias para o contexto democrático, como a resistência das forças de segurança ao controle civil, a mobilização da família (um elemento privado) como organizadora da esfera pública, a concepção meritocrática de direitos como sendo algo de natureza meritocrática;, o desejo por uma ordem social de conformidade moral e comportamental que não tolera o dissenso e o estatuto dessa ordem como hierarquicamente superior a outros direitos e aos meios para sua manutenção.

Em relação aos direitos humanos, observou-se um deslocamento fundamental. Nas primeiras legislaturas $\left(11^{\mathrm{a}}, 12^{\mathrm{a}}\right)$, os deputados apresentavam discursos de negação dessa política; contudo, por volta dos anos 2000 aparecem matizes de negociação e disputa pela interpretação e implementação dos direitos humanos, ponto mais acentuado na $18^{a}$ legislatura. Os deputados da "bancada da bala" buscaram ativamente participar de comissões e frentes parlamentares sobre o tema, especialmente das CPIs, e passaram a produzir projetos de lei individuais e coletivos em torno dessa pauta, centrados na categoria policial e nos atores enquadrados como vítimas do crime. 
Esse deslocamento complexifica o argumento que polariza o debate sobre direitos humanos entre grupos defensores e opositores. A importância de se estudar a estruturação desses grupos consiste justamente em observar as mudanças de atuação e de discursos em relação aos direitos humanos, o que aponta para formas distintas de apropriação e disputas de sentidos dessa política.

A análise aqui empreendida buscou mostrar que a estruturação desses grupos se estende para além das questões imediatas que se faz deles, geralmente baseadas na identidade policial, pauta corporativa, defesa de políticas de recrudescimento penal e agenda securitizadora. Foram observados os efeitos criativos das instrumentalizações que articulam percepções institucionais da polícia às representações e sensibilidades amplamente compartilhadas, como descrito por Caldeira (2000) sobre a fala do crime. Em outros termos, é preciso refletir sobre como esses elementos produzem identificação e legitimidade e combinam e atualizam percepções bastante enraizadas socialmente. Apesar desse enraizamento social, esses conteúdos são objeto constante de disputas, sendo repostos e transformados a todo momento.

Esses elementos e conteúdos acrescem discursos sobre o fenômeno da punição, que, por sua vez, fala à sociedade muito mais do que em termos de crime e castigo (GARLAND, 1995). Eles canalizam ansiedades e insatisfações diversas, produzem solidariedade entre grupos e organizam o mundo conforme territórios morais, apresentando grande potencial de circulação desses discursos e de adesão a eles. Assim, este artigo argumenta que os discursos mobilizados por "bancadas da bala" possibilitam comunicações com grupos e audiências diversos, reorganizando formas de conservadorismos nos campos de controle social e político. Em suma, a análise documental aqui empreendida abre novas possibilidades de compreensão desses grupos, uma vez que mostra como a trajetória de atuação dos “deputados-policiais” é mais complexa do que originalmente se pressupõe.

\section{Notas}

\footnotetext{
${ }^{1}$ As reflexões aqui apresentadas foram aprofundadas na dissertação de mestrado "Bancada da bala": Discursos e práticas sobre a punição, o crime e a insegurança na Assembleia Legislativa de São Paulo, defendida em 2018 no âmbito do Programa de Pós-Graduação em Sociologia (PPGS) da Universidade de São Paulo (USP) (NOVELLO, 2018).

${ }^{2}$ Major Olímpio (PSL) foi eleito em primeiro lugar para senador com mais de nove milhões de votos; Eduardo Bolsonaro (então PSL), policial federal, foi o deputado federal mais votado na história do país, com 1,75 milhão de votos. O general de reserva Elisier Girão Monteiro Filho foi o sexto deputado federal mais votado pelo Rio Grande do Norte, com 81.640 votos; a cabo Kátia Sastre foi a sétima candidata mais votada para deputada federal de São Paulo, com 264.013 votos; o capitão do Exército Renan Contar e o coronel Carlos Alberto David dos Santos (PSL) foram, respectivamente, o primeiro e o segundo deputado estadual mais votado do Mato Grosso do Sul. Coronel Telhada foi o terceiro deputado estadual de São Paulo com maior número de votos (cf. UOL, 08/10/2018). Disponível (on-line) em: https://www.tse.jus.br/

3 "Bancadas da bala" e/ou policiais na política são objetos incipientes, mas que vêm despertando cada vez mais interesse acadêmico. Para as principais publicações sobre o tema, ver Macaulay (2017, 2019), Miranda (2019), Quadros e Madeira (2018), Benetti (2017), Faganello (2015, 2017), Orban (2017), Berlatto, Codato e Bolognesi (2016) e Cymrot (2015).

${ }^{4}$ Considerando-se que esse fenômeno apresenta variações no legislativo federal, estadual e municipal, os parlamentos estaduais são relevantes para uma análise comparativa. A organização federativa do Brasil faz com que recursos
} 
disponíveis no plano estadual alimentem dinâmicas políticas próprias, subsistemas partidários e padrões de carreira e de produção legislativa bastante diferenciados (LIMA JÚNIOR, 1983, p. 963). Em suma, há agendas políticas e pautas decisórias própria dos estados (TOMIO e RICCl, 2012, p. 194).

${ }^{5}$ A transição democrática foi um período de descentralização do modelo de relações intergovernamentais montado pela ditadura militar em que governadores se fortaleceram no sistema político por meio da instituição de uma espécie de "federalismo estadualista" (ABRUCIO, 1994, pp. 166-170.).

${ }^{6}$ Em 2 de setembro de 1977 a Pontifícia Universidade Católica de São Paulo (PUC-SP) teve sua sede invadida por policiais e tropas de choque sob o comando do secretário de Segurança Pública Antônio Erasmo Dias, durante o $3^{\circ}$ Encontro Nacional de Estudantes. Dezenas de estudantes foram agredidos, presos e encaminhados para o Departamento de Ordem Política e Social (Dops). Disponível em: https://www.pucsp.br/comissaodaverdade/movimento-estudantil-invasao.html

${ }^{7}$ Adota-se aqui como referência as definições de Bobbio (1995) de esquerda e direita: indicam programas contrapostos em relação a problemas cuja solução pertence à ação política. A díade "extremismos-moderantismo" obedece ao critério de definição do método utilizado na ação política, o que é diverso da distinção entre esquerda e direita, cujo critério se dá em relação aos fins da ação política. Nesse sentido, o uso do termo extrema direita denota governos e movimentos que optam por estratégias extremas para além do eixo construído no consenso democrático entre direita e esquerda (Ibid., pp. 33-61).

${ }^{8}$ A policial militar ficou conhecida após a disseminação do vídeo. Ela foi homenageada pelo então governador Marcio França e, em 2018, foi eleita com 264 mil votos.

${ }^{9}$ Isso pode ser mensurado pela quantidade de votos que receberam em determinada eleição ou pela quantidade de vezes que foram reeleitos. Exemplos são Jair Bolsonaro, que foi deputado federal por 27 anos; Amaral Netto (PDS), aue teve oito mandatos parlamentares; e Paulo Maluf, eleito deputado federal com maior número de votos da história até 2002 (672.927 votos). Em 1986, Afanasio Jazadji foi recordista de votos (558.138) e permaneceu na Alesp até 2006.

${ }^{10}$ Como exemplos, temos a participação do coronel Telhada na Comissão de Direitos da Pessoa Humana e seu projeto de lei $n^{\circ}$ 600/2015, que visa à aplicação de sanções administrativas em estabelecimentos comerciais em casos de discriminação em virtude de raça, sexo, cor, origem, etnia, religião, idade, compleição física e orientação sexual. Para mais detalhes, ver Novello (2018).

${ }^{11}$ A Ouvidoria de Polícia do Estado de São Paulo foi a primeira do tipo no país, criada por meio do decreto no 39.900 , de $1^{\circ}$ de janeiro de 1995, pelo governador Mario Covas. Foi institucionalizada pela Alesp por meio da lei complementar $n^{\circ}$ $826 / 1997$.

${ }^{12} \mathrm{O}$ aumento de evangélicos na política e a possível sobreposição dos campos religioso e político são temas profícuos de pesquisa (cf. PRANDI e CARNEIRO, 2018).

${ }^{13}$ Para uma análise em profundidade das composições de frentes parlamentares, comissões permanentes, CPIs e produção legislativa, consultar Novello (2018).

14 Disponível (on-line) em: https://www.coronelcamilo.com.br/single-post/2015/08/17/coronel-camilo-lan\%C3\%A7afrente-parlamentar-em-defesa-da-fam\%C3\%ADlia-e-da-cidadania 


\section{Referências}

ABRUCIO, Fernando Luiz. “Os barões da federação”. Lua Nova, n. 33, pp. 165-183, 1994.

ADORNO, Sérgio; IZUMINO, Wânia Pasinato. "As graves violações de direitos humanos: O tema de pesquisa”. In: PINHEIRO, Paulo Sérgio. Continuidade autoritária e construção da democracia. Relatório de pesquisa, NEV-USP, 1999.

ALMEIDA, Ronaldo de. "A onda quebrada: Evangélicos e conservadorismo". Cadernos Pagu, n.50, e175001, 2017.

BENETTI, Pedro Rolo. "Em defesa da ordem": Debates parlamentares sobre a violência na Nova República. Tese (Doutorado em Ciência Política) - Universidade do Estado do Rio de Janeiro, Rio de Janeiro, 2017.

BERLATTO, Fabia, CODATO, Adriano; BOLOGNESI, Bruno. "Da polícia à política: Explicando o perfil dos candidatos das Forças Repressivas de Estado à Câmara dos Deputados”. Revista Brasileira de Ciência Política, no 21. Brasília, setembro - dezembro de 2016, pp 77-120

BOBBIO, Norberto. Direita e esquerda: Razões e significados de uma distinção polícia. Editora Unesp, São Paulo, 1995.

CALDEIRA, Teresa Pires do Rio. Cidade de Muros: Crime, segregação e cidadania em São Paulo. São Paulo: Ed. 34; Edusp. 2000.

CHAUÍ, Marilena. Manifestações ideológicas do autoritarismo brasileiro. Belo Horizonte: Autêntica, 2013.

CYMROT, Danilo. Polícia militante: Deputados policiais militares na Assembleia Legislativa de São Paulo (1999-2011). Tese (Doutorado em Direito) - Universidade de São Paulo, São Paulo, 2015.

FAGANELLO, Marco Antonio. O voto na Bancada da Bala: Estudo da geografia eleitoral na cidade de São Paulo (2012/2016). Dissertação (Mestrado em Ciência Política) - Universidad Estadual de Campinas, Campinas, 2017.

FAGANELLO, Marco Antonio. "Bancada da bala: uma onda na maré conservadora". In: CRUZ, Sebastião; KAYSEL, André; CODAS, Gustavo (orgs). Direita, volver! O retorno da direita e o ciclo político brasileiro. São Paulo: Fundação Perseu Abramo, 2015, pp. 145-161.

FOLHA DE S. PAULO. "Não sou contra a polícia”. Folha de S. Paulo, São Paulo, 20 nov. 1995.

FOUCAULT, Michel. A sociedade punitiva: Curso no Collège de France (1972-1973). São Paulo: WMF Martins Fontes, 2015.

FOUCAULT, Michel. A ordem do discurso: Aula inaugural no Collège de France, pronunciada em 2 de dezembro de 1970. São Paulo: Loyola, 2014.

FOUCAULT, Michel. A arqueologia do saber. Rio de Janeiro: Forense Universitária, 2008.

GARLAND, David. A cultura do controle. Rio de Janeiro: Revan, 2008.

GARLAND, David. “As contradições da sociedade punitiva: o caso britânico”. Rev. Sociol. Polit., Curitiba, n. 13, pp. 59-80, 1999. 
GARLAND, David. Punishment and Modern Society: A Study in Social Theory. Oxford, Claredon Press, 1995.

HIGA, Gustavo; ALVAREZ, Marcos César; SAlLA, Fernando. "Comissão Teotônio Vilela, redemocratização e políticas de humanização em São Paulo”. Revista do Arquivo, vol. 5, pp. 111-122, 2017.

LIMA JR., Olavo Brasil. Partidos políticos brasileiros: A experiência federal e regional 1945-64. Rio de Janeiro: Edições Graal, 1983.

MACAULAY, Fiona. "Bancada da Bala: The Growing Influence of the Security Sector in Brazilian Politics". In: FOLEY, Conor (org). In Spite of You: Bolsonaro and the New Brazilian Resistance. Nova York: OR Books, 2019, pp.56-70

MACAULAY, Fiona. "Presidents, Producers and Politics: Law-and-Order Policy in Brazil from Cardoso to Dilma”. Policy Studies, vol. 38, n. 3, pp. 248-261, 2017.

MANNHEIM, Karl. "O pensamento conservador". In: MARTINS, José de Souza (org). Introdução crítica à sociologia rural. São Paulo: Hucitec, 1986, pp.77-131.

MIRANDA, João Vitor Silva. Composição e atuação da "Bancada da Bala" na Câmara dos Deputados. Dissertação (Mestrado em Ciência Política) - Universidade Federal de Minas Gerais, Belo Horizonte, 2019.

MUNIZ, Jacqueline de Oliveira. "Ser policial é, sobretudo, uma razão de ser": Cultura e cotidiano da polícia militar do Estado de São Paulo. Tese (Doutorado em Ciência Política) - Instituto Universitário de Pesquisas do Rio de Janeiro, Rio de Janeiro, 1999.

NOVELLO, Roberta. "Bancada da bala": Discursos e práticas sobre punição, crime e insegurança na Assembleia Legislativa de São Paulo. Dissertação (Mestrado em Sociologia) - Universidade de São Paulo, São Paulo, 2018

O'DONNELL, Guillermo. "E eu com isso? Notas sobre sociabilidade e política na Argentina e no Brasil”. In: Contrapontos: Autoritarismo e democratização. São Paulo: Vértice, 1986, pp.121-151.

ORBAN, Vanessa. "Bancada da bala": Critérios de representação e identidade. Trabalho apresentado no $18^{\circ}$ Congresso Brasileiro de Sociologia, Brasília, 2017.

PINHEIRO, Paulo Sérgio. "Violência, crime e sistemas policiais em países de novas democracias". Tempo Social, São Paulo, vol. 1, n. 9, pp. 43-52, 1997

PINHEIRO, Paulo Sérgio. “Autoritarismo e transição”. Revista USP, n. 9, pp. 45-55, 1991.

PINHEIRO, Paulo Sérgio. “Polícia e crise política: o caso das polícias militares”. In: PAOLI, Maria Célia; BENEVIDES, Maria Victoria; PINHEIRO, Paulo Sérgio; DAMATTA, Roberto. A violência brasileira. São Paulo: Brasiliense, 1982, pp. 57-91.

PRANDI, Reginaldo; CARNEIRO, João Luiz. "Em nome do Pai: Justificativas do voto dos deputados federais evangélicos e não evangélicos na abertura do impeachment de Dilma Rousseff”. Rev. bras. Ci. Soc., São Paulo, vol. 33, n. 96, e339603, pp. 1-22, 2018.

QUADROS, Marcos Paulo dos Reis. Conservadorismo à brasileira: Sociedades e elites políticas na contemporaneidade. Tese (Doutorado em Ciências Sociais) - Pontifícia Universidade Federal do Rio Grande do Sul, Porto Alegre, 2015. 
QUADROS, Marcos Paulo dos Reis; Madeira, Rafael Machado. "Fim da direita envergonhada? Atuação da bancada evangélica e da bancada da bala e os caminhos da representação do conservadorismo no Brasil”. Opinião Pública, vol. 24, n. 3, pp. 486-522, 2018.

SOZZO, Maximo. "Transformações atuais das estratégias de controle do delito na Argentina: notas para a construção de uma cartografia do presente". In: CÂNEDO, Carlos; FONSECA, David (orgs). Ambivalência, contradição e volatilidade no Sistema Penal. Belo Horizonte: Editora UFMG, 2012, pp. 211-295.

TOMIO, Fabrício Ricardo de Limas; RICCI, Paolo. "O governo estadual na experiência política brasileira: os desempenhos legislativos das Assembleias Estaduais”. Rev. Sociol. Política, Curitiba, vol. 21, n. 41, pp. 193-217, 2012.

UOL. "Na esteira de Bolsonaro, 72 militares são eleitos para cargos legislativos". UOL, Eleições 2018, 8 out. 2018. Disponível em: https://noticias.uol.com.br/politica/eleicoes/2018/noticias/2018/10/08/militares-eleitos2018-camara-senado-assembleia-legislativa.htm

WACQUANT, Loic. “A tempestade global da lei e da ordem: sobre punição e neoliberalismo”. Rev. Sociol. Polít., Curitiba, vol. 20, n. 41, pp. 7-20, 2012.

WACQUANT, Loïc. As prisões da miséria. Rio de Janeiro: Zahar, 2011.

WACQUANT, Loïc . "Crafting the Neoliberal State: Workfare, Prisonfare, and Social Insecurity". Sociological Forum, vol. 25, n. 2, pp. 197-220, 2010.

WACQUANT, Loïc. Punishing the Poor: The Neoliberal Government of Social Insecurity. Durham: Duke University Press, 2009.

ZALUAR, Alba. "Violência e crime". In: MICELI, Sergio (org). O que ler na ciência social brasileira (1970-1999). São Paulo: Sumaré, 1999, pp. 13-107.

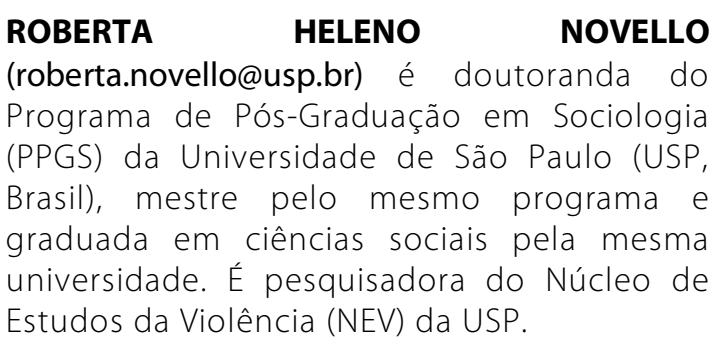

https://orcid.org/0000-0002-8680-491X

MARCOS CÉSAR ALVAREZ (mcalvarez@usp.br) é professor livre docente do Departamento de Sociologia da USP e coordenador do NEV/USP. É doutor e mestre pelo PPGS da USP e graduado em ciências sociais pela mesma universidade.

https://orcid.org/0000-0001-5984-9082 


\section{Colaboradores}

RHN foi responsável pela pesquisa empírica e pela concepção, análise, interpretação dos dados e redação final do artigo. MCA participou da concepção, interpretação, análise e revisão crítica do artigo.

Recebido em: 12/02/2021

Aprovado em: 16/08/2021 